\title{
Kiểm định hiệu ứng Tết nguyên đán trên thị trường chứng khoán Việt Nam
}

\section{The Lunar New Year effect on Vietnam stock market}

\author{
Trần Thị Tuấn Anh ${ }^{1 *}$ \\ ${ }^{1}$ Trường Đại học Kinh tế Thành phố Hồ Chí Minh, Việt Nam \\ *Tác giả liên hệ, Email: anhttt@ueh.edu.vn
}

THÔNG TIN

TÓM TÁT

DOI: $10.46223 /$ HCMCOUJS.

econ.vi.15.2.238.2020

Ngày nhận: 10/02/2020

Ngày nhận lại: 13/03/2020

Duyệt đăng: 19/03/2020

Tù khóa:

hiệu ứng Tết nguyên đán, hồi quy với biến giả, lý thuyết thị trường hiệu quả, thị trường chứng khoán Việt Nam

Keywords:

Lunar New Year effect, regression with dummy variables, efficient market hypothesis, Vietnam stock market
Bài viết sử dụng giá đóng cửa chứng khoán hàng ngày của thị trường chứng khoán trong giai đoạn 2010 - 2019 để kiểm định hiệu ứng Tết nguyên đán trên thị trường chứng khoán Việt Nam. Hiệu ứng Tết nguyên đán được xem xét với các độ dài cửa sổ dữ liệu lần lượt là $5 ; 10 ; 15$ và 30 ngày giao dịch trước và sau Tết. Kết quả cho thấy Tết nguyên đán có tác động tích cực đến thị trường, đặc biệt cho những ngày trước Tết. Ngày giao dịch càng xa ngày Tết nguyên đán thì tỷ suất sinh lợi trung bình càng giảm. Bài viết cũng cho thấy sự hiện diện hiệu ứng trước Tết nguyên đán ở các ngành Bất động sản, cao su, dược phẩm, năng lượng, sản xuất kinh doanh, vật liệu xây dựng và xây dựng. Các ngành bất động sản, cao su, dầu khí, dịch vụ, dịch vụ công ích, thép, thương mại và vận tải có hiệu ứng sau Tết nguyên đán. Kết quả nghiên cứu của bài viết còn là bằng chứng thực nghiệm cho tính không hiệu quả thông tin của thị trường chứng khoán Việt Nam.

\section{ABSTRACT}

The article uses the daily closing price of stock market in the period from 2010 to 2019 to determine the Lunar New Year (LNY) effect on the Vietnamese stock market with the window sizes of 5, 10, 15 and 30 days respectively. The results show that the LNY has a positive impact on the market, especially for the days before the Tet. The further trading day from LNY, the lower the average return. The article also shows the presence of preLNY effects on real estate, rubber, pharmaceuticals, energy, business, construction materials and construction. Real estate, rubber, oil and gas, services, utility services, steel, trade and transportation have the post-LNY effects. This article also provides empirical evidence for the information inefficiency of Vietnam's stock market. 


\section{Giới thiệu}

Giả thuyết thị trường hiệu quả do Fama (1970) đề xuất là một trong những lý thuyết kinh tế nền tảng của ngành Tài chính và thu hút được rất nhiều sự quan tâm của các nhà nghiên cứu trên khắp thế giới. Tính hiệu quả mà học thuyết đề cập chính là hiệu quả về mặt thông tin. Thị trường đạt trạng thái hiệu quả thông tin khi giá chứng khoán trên thị trường đã phản ánh đầy đủ các thông tin thị trường. Tùy theo mức độ phản ánh thông tin mà thị trường có thể được chia thành thị trường hiệu quả dạng yếu, dạng vừa và dạng mạnh.

Trong thị trường hiệu quả, mọi người đều có khả năng tiếp cận thông tin như nhau và các thông tin đã được phản ánh đầy đủ vào giá cả nên các biến động trên thị trường không có tính quy luật hoặc không có hình mẫu nào phù hợp để dự báo cho giá cả tương lai. Các nhà đầu tư sẽ ít, hoặc gần như không có cơ hội để tìm kiếm lợi nhuận vượt trội. Dựa trên đặc điểm này, một trong những hướng nghiên cứu phổ biến để kiểm định tính hiệu quả của thị trường chính là tìm ra tính hình mẫu của dữ liệu quá khứ và dùng tính hình mẫu này để dự báo cho các giá trị xảy ra trong tương lai. Sự tồn tại của tính hình mẫu trên dữ liệu thị trường là bằng chứng thống kê của việc thị trường không đạt trạng thái hiệu quả thông tin. Rất nhiều các nghiên cứu thực nghiệm được thực hiện theo chiều hướng này và đạt được các kết quả nghiên cứu có ý nghĩa. Trong số các mô hình thể hiện tính hình mẫu trên thị trường, có thể kể đến các nghiên cứu kiểm định các hiệu ứng đặc biệt của thị trường như hiệu ứng ngày thứ Hai, hiệu ứng cuối tuần, hiệu ứng chuyển tháng, hiệu ứng trăng tròn, hiệu ứng kỳ nghỉ lễ...

Bài viết này tiếp tục kế thừa ý tưởng nghiên cứu trên để tiến hành khảo sát thêm tính hiệu quả thị trường chứng khoán Việt Nam thông qua việc kiểm định hiệu ứng của ngày Tết nguyên đán bằng các mô hình hồi quy.

\section{Tổng quan lý thuyết}

Trong tổng quan các nghiên cứu về các dạng hiệu quả trên thị trường, đã có rất nhiều các nghiên cứu kiểm định các hiệu ứng của những thời điểm hoặc khoảng thời gian đặc biệt đối với thị trường.

Dichev và Janes (2001) nghiên cứu về ảnh hưởng của chu kỳ trăng đối với lợi nhuận chứng khoán với dữ liệu về chỉ số trung bình công nghiệp từ Dow Jones và chỉ Standard and Poor's 500. Kết quả nghiên cứu cho thấy tỷ suất lợi nhuận chứng khoán xung quanh ngày trăng non cao hơn gấp đôi so với ngày trăng tròn. Kết quả này tương tự cho tất cả các chỉ số chứng khoán lớn của Mỹ như chỉ số DJIA, S\&P 500, NYSE-AMEX và Nasdaq. Nhóm tác giả đã sử dụng dữ liệu Datastream để nghiên cứu cho 24 thị trường trên thế giới trong vòng 30 năm và cho kết quả không có sự khác biệt nhiều. Cụ thể là tỷ suất lợi nhuận hàng ngày xung quanh kỳ trăng non hơn gấp đôi tỷ suất lợi nhuận hàng ngày xung quanh kỳ trăng tròn tại 6 thị trường (Đức, Canada, Hà Lan, Ireland, Indonesia và Singapore).

Yuan, Zheng và Zhu (2006) nghiên cứu về mối liên hệ giữa các kỳ trăng và lợi nhuận chứng khoán ở 48 quốc gia trong thời gian từ tháng 01 năm 1973 đến tháng 07 năm 2001 . Nhóm tác giả sử dụng dữ liệu về chu kỳ trăng gồm: trăng non, trăng bán nguyệt đầu tháng, trăng tròn, trăng bán nguyệt cuối và xem xét hiệu ứng của các chu kỳ trăng trên thị trường. Kêt quả nghiên cứu cho thấy những bằng chứng mạnh mẽ về hiệu ứng này trên thế giới, biểu thị bằng việc lợi nhuận chứng khoán thấp hơn vào các ngày gần trăng tròn so với các ngày gần trăng non.

Yuan và Gupta (2014) thu thập dữ liệu từ các thị trường chứng khoán Trung Quốc, Hong Kong, Nhật Bản, Malaysia, Hàn Quốc và Đài Loan trong giai đoạn từ 01/09/1999 đến 
28/03/2012 để kiểm định hiệu ứng ngày nghỉ lễ ứng với dịp Tết nguyên đán trên thị trường. số liệu trên được khảo sát trong giai đoạn từ 01/09/1999 đến 28/03/2012. Tác giả sử dụng hai biến giả $D_{\text {pre và }} D_{\text {post }}$ ứng với khoảng thời gian 3 ngày trước và sau kỳ nghỉ Tết nguyên đán của các thị trường. Kết quả cho thấy Hàn Quốc là nước có hiệu ứng bị ảnh hưởng rõ nét nhất bởi hiệu ứng này khi ghi nhận lợi nhuận trong 3 ngày giao dịch trước Tết tăng $0.68 \%$. Các quốc gia khác trong mẫu kiểm định cũng tồn tại hiệu ứng này nhưng không mạnh mẽ như ở Hàn Quốc.

Bên cạnh các nghiên cứu trên thế giới, các nghiên cứu trong nước cũng đã được thực hiện rất nhiều để kiểm chứng các hiệu ứng này trên thị trường Việt Nam. Tram, Vo, và Nguyen (2015) đã kiểm định hiệu ứng ngày thứ hai trên thị trường chứng khoán Việt Nam. Phương pháp hồi quy thực hiện là phương pháp hồi quy với biến giả cho hai giai đoạn trước (20002007) và sau khủng hoảng (2008-2012). Kết quả nghiên cứu của nhóm tác giả cho thấy giai đoạn trước khủng hoảng (2000-2007) hiệu ứng ngày thứ hai có tồn tại trên thị trường chứng khoán Việt Nam. Trong đó tỷ suất sinh lợi của ngày thứ sáu cao hơn ngày thứ hai, tuy nhiên lại không đủ chứng cứ kết luận điều tương tự với tỷ suất sinh lợi các ngày thứ ba, tư, năm so với ngày thứ hai... Ngược lại, ở giai đoạn trong và sau khủng hoảng (2008-2012) hiệu ứng ngày thứ hai không còn tồn tại.

Le và Truong (2018) sử dụng dữ liệu trong giai đoạn 2005 đến 2016 của Việt Nam và tám quốc gia châu Ả khác để kiểm định hiệu ứng kỳ nghỉ Tết nguyên đán trên các thị trường chứng khoán. Kết quả của nhóm tác giả cho thấy, hiệu ứng kỳ nghỉ Tết Âm lịch tồn tại ở năm quốc gia là Việt Nam, Malaysia, Nhật Bản, Hồng Kông, Đài Loan. Trong đó, hiệu ứng trước kỳ nghỉ Tết Âm lịch tồn tại ở ba quốc gia là Việt Nam, Malaysia, Nhật Bản và hiệu ứng sau kỳ nghỉ Tết Âm lịch tồn tại ở hai quốc gia là Hồng Kông và Đài Loan.

Trong các nghiên cứu trên, sự tồn tại của hiệu ứng ngày thứ hai, hiệu ứng chu kỳ trăng, hiệu ứng chuyển tháng, hiệu ứng Tết nguyên đán, ... là bằng chứng thực nghiệm cho thấy tính hình mẫu của dữ liệu. Tính hình mẫu tồn tại trong chuỗi tỷ suất sinh lợi là là bằng chứng thống kê của việc thị trường không đạt trạng thái hiệu quả thông tin. Hay nói một cách khác, các nhà đầu tư có thể dựa vào tính hình mẫu này để tìm kiếm tỷ suất sinh lợi vượt trội; và đây cũng là bằng chứng thực nghiệm chống lại giả thuyết thị trường hiệu quả của Fama (1970).

Kế thừa nghiên cứu về tác động của kỳ nghỉ Tết nguyên đán tham khảo từ nghiên cứu của Yuan và Gupta (2014), bài viết này thực hiện kiểm định hiệu ứng kỳ nghỉ Tết nguyên đán trên thị trường chứng khoán Việt Nam nhưng kiểm định với nhiều độ dài khung cửa sổ khác nhau xung quanh kỳ nghỉ Tết nguyên đán. Việc kiểm định được thực hiện cho toàn bộ thị trường dựa trên chỉ số VN-Index cũng như kiểm định cho từng ngành trên thị trường thông qua các chỉ số ngành.

\section{Phương pháp nghiên cứu}

\subsection{Số liệu}

Bài viết sử dụng giá đóng cửa hàng ngày của chỉ số Việt Nam-Index thu thập trong giai đoạn từ đầu tháng 01 năm 2010 đến hết tháng 12 năm 2019. Đây là giai đoạn sau khủng hoảng trên thị trường trong nước và thế giới. Hình 1 biểu diễn đường biến động của giá đóng cửa hàng ngày của VN-Index và Hình 2 thể hiện biến động của tỷ suất sinh lợi hàng ngày. Tỷ suất sinh lợi hàng ngày của $\mathrm{VN}$-Index được tính toán bằng công thức logarit tỷ số giá hôm sau chia cho giá hôm trước và được quy đổi về dạng phần trăm. 


$$
R_{t}=100 \times \ln \frac{P_{t}}{P_{t-1}}
$$

\subsection{Phương pháp nghiên cúu}

Để thực hiện kiểm định tác động của ngày Tết nguyên đán hàng năm với thị trường chứng khoán Việt Nam, bài viết sử dụng mô hình GARCH $(1,1)-\mathrm{AR}$ (1) kết hợp với biến giả tương ứng với giai đoạn giao dịch những ngày giáp Tết nguyên đán và những ngày sau Tết. Mô hình GARCH-AR ước lượng bằng phương pháp hợp lý cực đại được sử dụng thay cho mô hình hồi quy tuyến tính thông thường được ước lượng bằng OLS. Điều này được thực hiện vì phương pháp OLS đòi hỏi nhiều giả thiết nghiêm ngặt về tính chất của dữ liệu và mô hình như sai số cần có phân phối chuẩn, không có tự tương quan và phương sai thuần nhất; trong khi các chuỗi dữ liệu thực tế như tỷ suất sinh lợi thường rất khó thỏa mãn các giả thiết này.

Mô hình GARCH-AR của chuỗi tỷ suất sinh lợi thường có hai phương trình; một phương trình trung bình (mean equation) để mô hình hóa chuỗi tỷ suất sinh lợi và phương trình phương sai (variance equation) để mô tả phương sai thay đổi của chúng. Trong bài viết này, để thực hiện mục tiêu kiểm định hiệu ứng của ngày Tết nguyên đán, biến giả được sử dụng trong phương trình trung bình với hai trường hợp khác nhau để xem xét các tác động một cách cụ thể trên nhiều khía cạnh, đồng thời để kiểm chứng tính ổn định của kết quả mà bài viết đạt được. Hai trường hợp sử dụng biến giả như sau:

\section{Trương hợp sủ dụng một biến giả}

$$
D_{-} \text {Tdays }_{t}=\left\{\begin{array}{l}
1 \text { if } t \in[-T, T] \\
0 \text { if } t \notin[-T, T]
\end{array}\right.
$$

Nghĩa là biến giả $D \_T d a y s$ nhận giá trị 1 nếu thời điểm được xét nằm trong khung cửa sổ thời gian từ $\mathrm{T}$ ngày giao dịch trước Tết đến $\mathrm{T}$ ngày giao dịch sau Tết. Những ngày giao dịch trước Tết được đánh số âm để phân biệt với những ngày sau Tết được đánh số dương.

Trong bài viết này, độ dài cửa sổ $T$ được xét lần lượt ở 4 mức khác nhau gồm 5 ngày, 10 ngày, 15 ngày và 30 ngày. Mô hình $\operatorname{GARCH}(1,1)-\mathrm{AR}$ (1) trong trường hợp có một biến giả cho sự kiện Tết nguyên đán được biểu diễn như sau:

$$
\begin{aligned}
& R_{t}=\beta_{0}+\beta_{1} R_{t-1}+\theta D_{-} \text {Tdays }_{t}+\varepsilon_{t} \\
& \varepsilon_{t}^{2} \mid I_{t-1} \sim N\left(0, \sigma_{t}^{2}\right) \\
& \sigma_{t}^{2}=\alpha_{0}+\alpha_{1} \varepsilon_{t-1}^{2}+\lambda \sigma_{t-1}^{2}
\end{aligned}
$$

Hệ số $\theta$ trong phương trình (3) cho biết sự khác biệt về tỷ suất sinh lợi trung bình trong giai đoạn trong và ngoài cửa sổ dữ liệu của những ngày Tết. Dấu và độ lớn của hệ số $\theta$ sẽ giúp xác nhận bằng chứng thống kê cho sự ảnh hưởng của ngày Tết nguyên đán đến thị trường chứng khoán.

Trường hợp sư dụng hai biến giả

Khi đó, hai biến giả tương ứng với khung thời gian giao dịch trước và sau kỳ nghỉ Tết nguyên đán được đặt tên là $D$ Tdays_before và $D$ Tdays_after với quy ước như sau: 


$$
\begin{aligned}
& D_{-} \text {Tdays_before }_{t}=\left\{\begin{array}{c}
1 \text { if } t \in[-T,-1] \\
0 \text { if } t \notin[1, T]
\end{array}\right. \\
& D_{-} \text {Tdays_after }{ }_{t}=\left\{\begin{array}{c}
0 \text { if } t \in[-T,-1] \\
1 \text { if } t \notin[1, T]
\end{array}\right.
\end{aligned}
$$

Khi đó, mô hình GARCH (1,1)-AR (1) với hai biến giả sẽ được thực hiện như sau:

$$
\begin{aligned}
& R_{t}=\beta_{0}+\beta_{1} R_{t-1}+\theta_{\text {before }} D_{-} T d a y s_{-} \text {before } t_{t}+\theta_{\text {after }} D_{-} \text {Tdays_after }_{t}+\varepsilon_{t} \\
& \varepsilon_{t}^{2} \mid I_{t-1} \sim N\left(0, \sigma_{t}^{2}\right) \\
& \sigma_{t}^{2}=\alpha_{0}+\alpha_{1} \varepsilon_{t-1}^{2}+\lambda \sigma_{t-1}^{2}
\end{aligned}
$$

Hệ số hồi quy $\theta b e f o r e$ và $\theta a f t e r$ sẽ cho biết sự khác biệt trong tỷ suất sinh lợi của các giao dịch chứng khoán của giai đoạn $T$ ngày giao dịch trước và sau khi thị trường chứng khoán trải qua kỳ nghỉ Tết. Sự tác động của Tết nguyên đán với thị trường chứng khoán Việt Nam thể hiện ở ý nghĩa thống kê, dấu và độ lớn của các biến giả này.

Bên cạnh việc kiểm định hiệu ứng Tết nguyên đán trên thị trường dựa vào chỉ số VNIndex, bài viết còn ước lượng mô hình (5) trên chỉ số chứng khoán của từng ngành trên thị trường chứng khoán Việt Nam để phân tích chi tiết hơn về sự tác động của Tết nguyên đán đến thị trường.

\section{Kết quả nghiên cứu và thảo luận}

\subsection{Thống kê mô tả dũ liệu}

Hình 1 thể hiện đồ thị của chuỗi giá đóng cửa hàng ngày của chỉ số VN-Index trong giai đoạn từ đầu tháng 01 năm 2010 đến hết tháng 12 năm 2019 và Hình 2 thể hiện biến động tỷ suất sinh lợi hàng ngày được tính từ giá đóng cửa theo công thức (1). Các kết quả thống kê mô tả của chuỗi giá đóng cửa và chuỗi tỷ suất sinh lợi hàng ngày được thể hiện ở Bảng 1 .

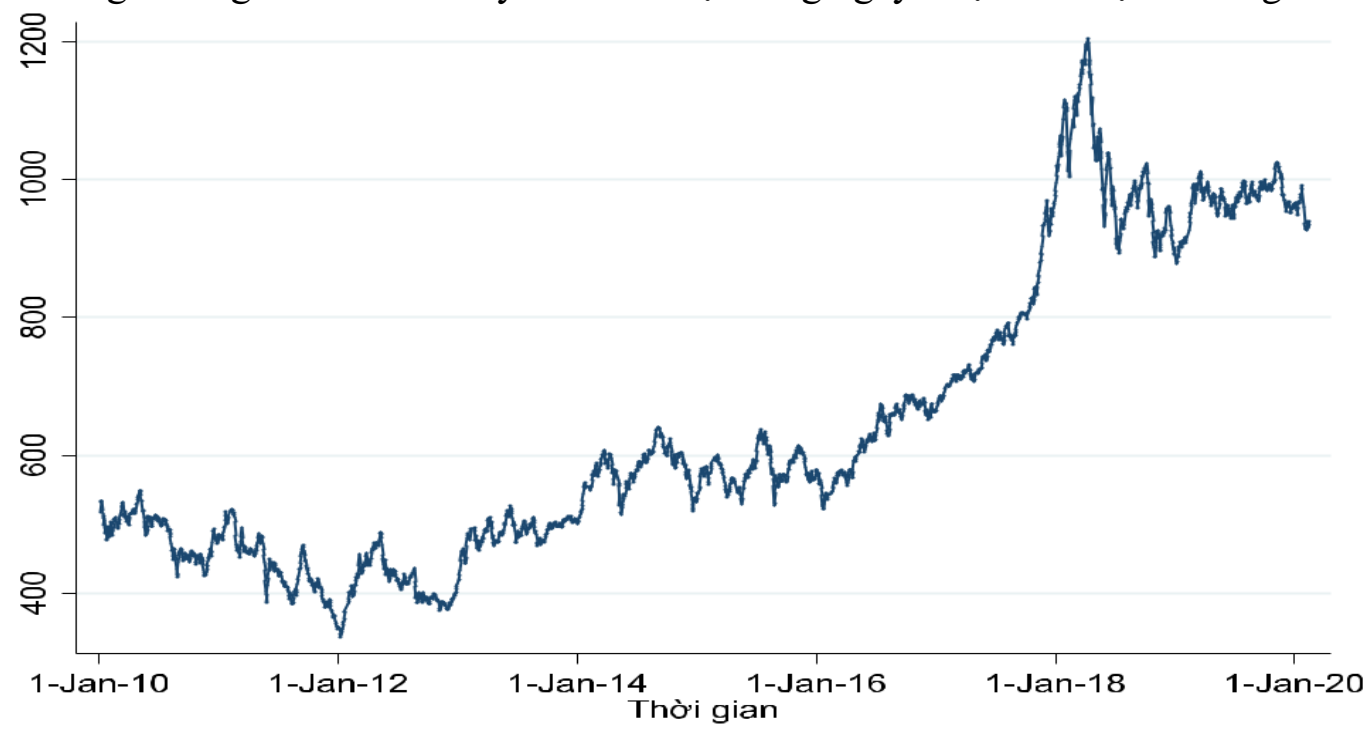

Hình 1. Giá đóng cửa hàng ngày của chỉ số VN-Index

Nguồn: Tác giả vẽ từ số liệu thu thập được bằng phần mềm Stata 


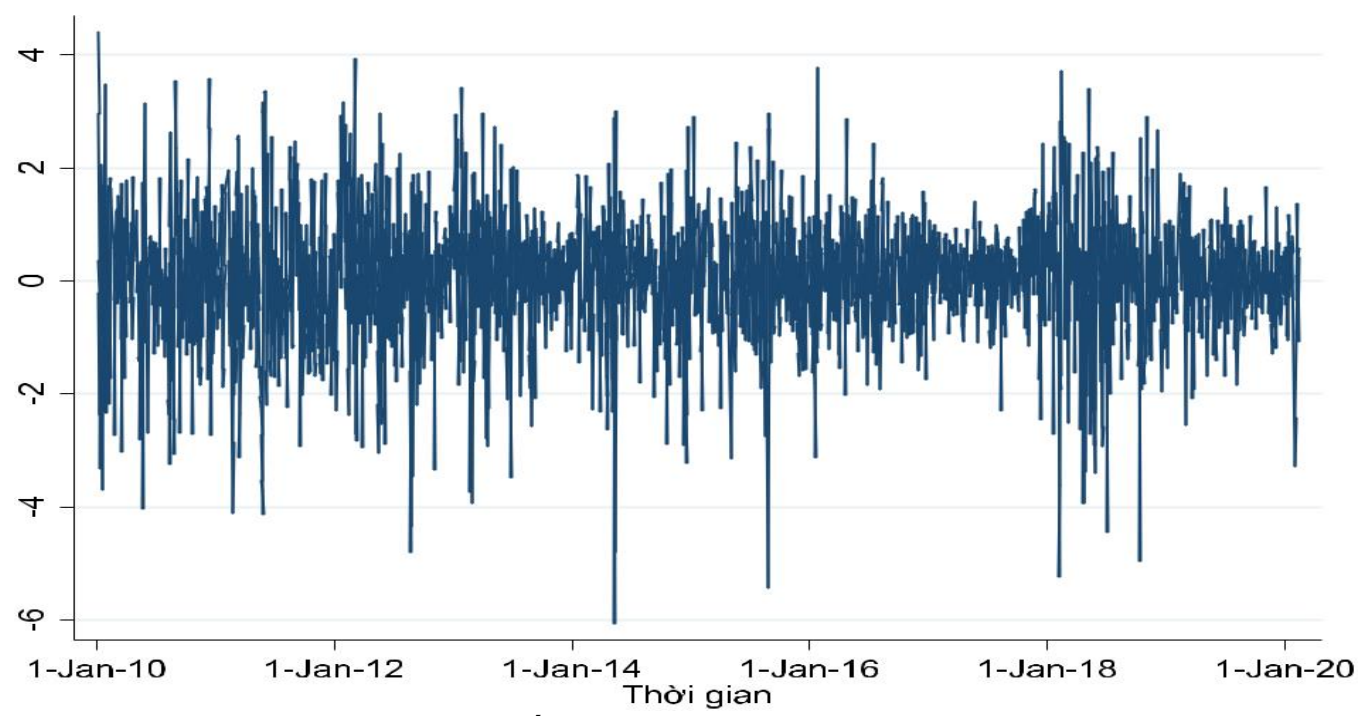

Hình 2. Tỷ suất sinh lợi hàng ngày của VN-Index

Nguồn: Tác giả vẽ từ số liệu thu thập được bằng phần mềm Stata

Theo các chỉ tiêu thống kê mô tả được tính ở Bảng 1, giá trị trung bình của tỷ suất sinh lợi giai đoạn 2010 - 2019 là $0,05 \%$. Giá trị trung bình mang dấu dương cho thấy khả năng sinh lợi của thị trường. Kiểm định tính dừng của chuỗi tỷ suất sinh lợi bằng cả hai phương pháp Dickey-Fuller mở rộng và phương pháp Phillip-Perron để cho thấy chuỗi dừng, kiểm định này giúp tránh trường hợp kết quả hồi quy thu được là giả mạo.

\section{Bảng 1}

Thống kê mô tả giá đóng cửa hàng ngày và tỷ suất sinh lợi của VN-Index

\begin{tabular}{|c|c|c|}
\hline Chỉ tiêu & $\begin{array}{c}\text { Giá đóng cửa hàng } \\
\text { ngày }\end{array}$ & $\begin{array}{c}\text { Tỷ suất sinh lọii hàng } \\
\text { ngày }\end{array}$ \\
\hline Số quan sát & 2518 & 2518 \\
\hline Trung bình & 625,17 & 0,05 \\
\hline Trung vị & 570,23 & 0,03 \\
\hline Độ lệch chuẩn & 200,69 & 1,10 \\
\hline Kiểm định ADF & & $-45,11 * * *$ \\
\hline Kiểm định Phillip-Perron & & $-45,10 * * *$ \\
\hline
\end{tabular}

***,**,* tương ứng với mức ý nghĩa $1 \%, 5 \%$ và $10 \%$

Nguồn: Tác giả tính toán từ số liệu thu thập được

Bảng 2 thể hiện thống kê mô tả của giá đóng cửa và tỷ suất sinh lợi hàng ngày của VNIndex theo từng năm. Trong giai đoạn sau khủng hoảng này, tỷ suất sinh lợi trung bình của năm 2010 và 2011 mang dấu âm, đây là khoảng thời gian ngay sau khủng hoảng nên thị trường cần thời gian để hồi phục. Ngoài ra, năm 2018 cũng có tỷ suất sinh lợi trung bình mang dấu âm. Nhìn lại các sự kiện năm 2018 cũng có thể thấy đây là một năm thị trường có những biến động ngoạn mục, khi mà thị trường mua bán sôi nổi và VN-Index tạo đỉnh 1200 điểm vào tháng 4 , và sau đó là những phiên giảm kịch sàn do ảnh hưởng từ thị trường quốc tế. 


\section{Bảng 2}

Thống kê mô tả VN-Index theo từng năm

\begin{tabular}{ccccc}
\hline \multirow{2}{*}{ Năm } & \multicolumn{2}{c}{ Giá đóng cửa chỉ số VN-Index } & \multicolumn{2}{c}{ Tỷ suất sinh lọ̣i } \\
\cline { 2 - 5 } & Trung bình & Độ lệch chuẩn & Trung bình & Độ lệch chuẩn \\
\hline 2010 & 486.050 & 1.897 & -0.008 & 0.084 \\
2011 & 434.598 & 2.566 & -0.129 & 0.085 \\
2012 & 412.831 & 1.928 & 0.065 & 0.080 \\
2013 & 490.115 & 1.130 & 0.079 & 0.068 \\
2014 & 579.951 & 1.888 & 0.032 & 0.071 \\
2015 & 579.882 & 1.469 & 0.024 & 0.067 \\
2016 & 625.907 & 3.008 & 0.055 & 0.056 \\
2017 & 780.169 & 4.864 & 0.157 & 0.039 \\
2018 & 1008.539 & 5.171 & -0.039 & 0.089 \\
2019 & 971.525 & 1.779 & 0.030 & 0.043 \\
\hline Toàn bộ mẫu & $\mathbf{5 2 6 . 5 4 3}$ & $\mathbf{2 6 6 . 2 8 3}$ & $\mathbf{0 . 0 4 7}$ & $\mathbf{1 . 4 8 0}$ \\
\hline
\end{tabular}

***,**,* tương ứng với mức ý nghĩa $1 \%, 5 \%$ và $10 \%$

Nguồn: Tác giả tính toán từ số liệu thu thập được

Trong giai đoạn này, năm 2017 có tỷ suất sinh lợi trung bình hàng ngày cao nhất với $0,15 \%$ và năm 2011 có tỷ suất sinh lợi trung bình thấp nhất với giá trị khoảng $-0,13 \%$.

\subsection{Kết quả nghiên cúu và thảo luận}

Trước khi thực hiện hồi quy theo mô hình (4) và (5) để xem xét tác động của Tết nguyên đán đến thị trường, bài viết thực hiện một vài tính toán mang tính chất mô tả để giúp có được những nhận định ban đầu về tác động của kỳ nghỉ Tết nguyên đán. Bảng 3 thể hiện giá trị trung bình và chênh lệnh giá trị trung bình của tỷ suất sinh lợi của giai đoạn trong và ngoài cửa sổ Tết cũng như của giai đoạn trước và sau Tết. Các tính toán được thực hiện với độ dài $T$ của khung cửa sổ Tết lần lượt là 5 ngày, 10 ngày, 15 ngày và 30 ngày. Khung cửa sổ có độ dài $T$ có nghĩa là khoảng thời gian được xét là $T$ ngày trước Tết và $T$ ngày sau Têt.

Kết quả tính toán thể hiện ở cột (3) ở tất cả các cửa sổ độ dài $T$ đều cho thấy tỷ suất sinh lợi trung bình của những ngày giao dịch xung quanh kỳ nghỉ Tết cao hơn rất nhiều so với những ngày cách xa kỳ nghỉ Tết. Cụ thể, tỷ suất sinh lợi trung bình của khung của sổ từ 5 ngày giao dịch trước Tết đến 5 ngày giao dịch sau Tết là $0,27 \%$; cao hơn rất nhiều so với giá trị trung bình của tất cả những ngày giao dịch khác, chỉ ở mức $0,014 \%$. Kết quả tương tự cũng đạt được với các khung cửa sổ $T=10 ; 15$ và 30 ngày xung quanh kỳ nghỉ Têt. Đây là dấu hiệu ban đầu cho thấy sự kiện Tết nguyên đán có tác động tích cực tới thị trường. 


\section{Bảng 3}

Chênh lệch tỷ suất sinh lợi trung bình giai đoạn trong và ngoài Tết, trước Tết và sau Tết

\begin{tabular}{|c|c|c|c|c|}
\hline Độ dài cử & Chỉ tiêu & Tỷ suất sinh lọii & Chỉ tiêu & Tỷ suất sinh lọii \\
\hline (1) & $(2)$ & (3) & (4) & (5) \\
\hline \multirow{4}{*}{$\begin{array}{c}\text { Cửa sổ } 5 \\
\text { ngày }\end{array}$} & & & Trung bình trước & \\
\hline & Trung bình trong Tết & 0.276 & Tết & 0.366 \\
\hline & Trung bình ngoài Tết & 0.014 & Trung bình sau Tết & 0.187 \\
\hline & Chênh lệch & 0.262 & Chênh lệch & 0.179 \\
\hline \multirow{4}{*}{$\begin{array}{c}\text { Cửa sổ } 10 \\
\text { ngày }\end{array}$} & & & Trung bình trước & \\
\hline & Trung bình trong Tết & 0.267 & Tết & 0.359 \\
\hline & Trung bình ngoài Tết & 0.025 & Trung bình sau Tết & 0.174 \\
\hline & Chênh lệch & 0.242 & Chênh lệch & 0.185 \\
\hline \multirow{4}{*}{$\begin{array}{c}\text { Cửa sổ } 15 \\
\text { ngày }\end{array}$} & & & Trung bình trước & \\
\hline & Trung bình trong Tết & 0.185 & Tết & 0.248 \\
\hline & Trung bình ngoài Tết & 0.002 & Trung bình sau Tết & 0.120 \\
\hline & Chênh lệch & 0.183 & Chênh lệch & 0.128 \\
\hline \multirow{4}{*}{$\begin{array}{c}\text { Cửa sổ } 30 \\
\text { ngày }\end{array}$} & & & Trung bình trước & \\
\hline & Trung bình trước Tết & 0.130 & Tết & 0.166 \\
\hline & Trung bình sau Tết & -0.01 & Trung bình sau Tết & 0.092 \\
\hline & Chênh lệch & 0.140 & Chênh lệch & 0.074 \\
\hline
\end{tabular}

Nguồn: Tác giả tính toán từ số liệu thu thập được

Một kết quả khác cũng có thể nhận thấy từ kết quả mô tả ở Bảng 4 đó là khi độ dài khung cửa sổ ngày giao dịch quanh kỳ nghỉ tết càng dài thì tỷ suất sinh lợi trung bình càng thấp; có nghĩa là càng gần Tết thì tỷ suất sinh lợi trung bình càng cao và những ngày càng xa ngày Tết thì tỷ suất sinh lợi trung bình càng thấp. Các kết quả ước lượng và kiểm định tác động của Tết nguyên đán đến thị trường theo mô hình (3) và (5) được thể hiện lần lượt ở Bảng 4 và Bảng 5 .

\section{Bảng 4}

Mô hình GARCH $(1,1)$ - AR (1) với một biến giả cho cửa sổ số liệu trong và ngoài Tết

\begin{tabular}{|c|c|c|c|c|}
\hline \multicolumn{5}{|c|}{ Tỷ suất sinh lọ̣i } \\
\hline Biến độc lập & 5 ngày & 10 ngày & 15 ngày & 30 ngày \\
\hline (1) & (2) & (3) & (4) & (5) \\
\hline \multicolumn{5}{|c|}{ Phương trình trung bình } \\
\hline \multirow[t]{2}{*}{ D_5days } & $0.234 * *$ & & & \\
\hline & [2.39] & & & \\
\hline \multirow[t]{2}{*}{ D_10days } & & $0.209 * * *$ & & \\
\hline & & [3.35] & & \\
\hline \multirow[t]{2}{*}{ D_15days } & & & $0.150 * * *$ & \\
\hline & & & {$[2.67]$} & \\
\hline \multirow[t]{2}{*}{ D_30days } & & & & $0.0967 * *$ \\
\hline & & & & [2.11] \\
\hline Hệ số chặn & $0.0391 *$ & 0.0305 & 0.0301 & 0.0246 \\
\hline
\end{tabular}




\begin{tabular}{|c|c|c|c|c|}
\hline \multicolumn{5}{|c|}{ Tỷ suất sinh lợi } \\
\hline Biến độc lập & 5 ngày & 10 ngày & 15 ngày & 30 ngày \\
\hline \multirow[t]{2}{*}{ (1) } & (2) & (3) & (4) & (5) \\
\hline & {$[1.80]$} & {$[1.36]$} & {$[1.31]$} & {$[0.98]$} \\
\hline \multirow[t]{2}{*}{ L.ar } & $0.0868 * * *$ & $0.0842 * * *$ & $0.0848 * * *$ & $0.0883 * * *$ \\
\hline & [3.23] & [3.12] & [3.15] & [3.28] \\
\hline \multicolumn{5}{|c|}{ Phương trình phương sai } \\
\hline \multirow[t]{2}{*}{ L.arch } & $0.205^{* * *}$ & $0.203 * * *$ & $0.203 * * *$ & $0.203 * * *$ \\
\hline & [7.12] & {$[7.05]$} & {$[7.05]$} & {$[7.06]$} \\
\hline \multirow[t]{2}{*}{ L.garch } & $0.747 * * *$ & $0.745^{* * *}$ & $0.744 * * *$ & $0.745^{* * *}$ \\
\hline & {$[10.28]$} & {$[10.15]$} & {$[10.13]$} & {$[10.13]$} \\
\hline \multirow[t]{2}{*}{ Hệ số chặn } & 0.0238 & 0.0275 & 0.0279 & 0.0279 \\
\hline & [0.39] & {$[0.44]$} & {$[0.45]$} & {$[0.45]$} \\
\hline Số quan sát & 2518 & 2518 & 2518 & 2518 \\
\hline
\end{tabular}

***,**,* tương ứng với mức ý nghĩa $1 \%, 5 \%$ và $10 \%$

Nguồn: Tác giả tính toán từ số liệu thu thập được

Bảng 4 được hồi quy theo mô hình (3) với 1 biến giả $D \_T d a y s$ được sử dụng để phân biệt giai đoạn trong cửa sổ những ngày giao dịch gần kỳ nghỉ Tết với những ngày giao dịch xa kỳ nghỉ Tết. Các cột (2), (3), (4) và (5) của Bảng 4 lần lượt ứng với chiều dài cửa sổ là $5,10,15$ và 30 ngày trước và sau kỳ nghỉ Tết của thị trường. Các thành phần $\mathrm{AR}, \mathrm{ARCHvà} \mathrm{GARCH}$ trong mô hình ở Bảng 4 đều có ý nghĩa thống kê và thỏa mãn các ràng buộc của mô hình GARCH thông thường, điều này cho thấy sự cần thiết và phù hợp khi sử dụng mô hình GARCH $(1,1)-\mathrm{AR}(1)$ để thực hiện ý tưởng nghiên cứu của đề tài. Kết quả cho thấy trong tất cả các chiều dài cửa sổ $T$ được xét, biến giả $D_{-}$Tdays luôn mang dấu dương và có ý nghĩa thống kê. Trong điều kiện các yếu tố khác không đổi, tỷ suất sinh lợi của những ngày giao dịch trong cửa sổ 5 ngày gần Tết, không phân biệt trước và sau tết, cao hơn tỷ suất sinh lợi của những ngày khác và mức chênh lệch theo kết quả ước lượng là $20,23 \%$. Con số chênh lệch nhỏ dần khi độ dài $T$ lớn dần, cụ thể, mức chênh lệch lần lượt là $0,209 \% ; 0,15 \%$ và $0,09 \%$ ứng với $T=10 ; 15$ và 30 . Kết quả nghiên cứu ban đầu cho thấy kỳ nghỉ Tết có tác động tích cực đến thị trường; càng gần ngày nghỉ Tết, tỷ suất sinh lợi càng cao và càng xa kỳ nghỉ Tết tỷ suất sinh lợi càng thấp. Hơn thế nữa, ý nghĩa thống kê trong sự tác động của Tết đến thị trường cũng chính là một bằng chứng thực nghiệm cho tính không hiệu quả của thị trường chứng khoán Việt Nam; nó cho thấy tính hình mẫu trong số liệu thị trường, khi mà dựa vào đó nhà đầu tư có thêm thông tin để có thể tìm kiếm tỷ suất sinh lợi bất thường.

\section{Bảng 5}

Mô hình GARCH $(1,1)$ - AR (1) với 02 biến giả cho cửa sổ số liệu trước và sau Tết

\begin{tabular}{ccccc}
\hline Biến độc lập & $\mathbf{5}$ ngày & $\mathbf{1 0}$ ngày & $\mathbf{1 5}$ ngày & 30 ngày \\
\hline (1) & $(\mathbf{2})$ & $\mathbf{( 3 )}$ & $\mathbf{( 4 )}$ & (5) \\
\hline \multicolumn{5}{c}{} \\
\hline D_5days_before & $0.333^{* *}$ & Phương trình trung bình \\
& {$[2.06]$} & & \\
D_5days_after & 0.098 & &
\end{tabular}




\begin{tabular}{|c|c|c|c|c|}
\hline Biến độc lập & 5 ngày & 10 ngày & 15 ngày & 30 ngày \\
\hline \multirow[t]{2}{*}{ (1) } & $(2)$ & (3) & (4) & (5) \\
\hline & [0.86] & & & \\
\hline \multirow[t]{2}{*}{ D_10days_before } & & $0.323^{* * *}$ & & \\
\hline & & {$[3.64]$} & & \\
\hline \multirow[t]{2}{*}{ D_10days_after } & & 0.0942 & & \\
\hline & & [1.18] & & \\
\hline \multirow[t]{2}{*}{ D_15days_before } & & & $0.233 * * *$ & \\
\hline & & & [2.94] & \\
\hline \multirow[t]{2}{*}{ D_15days_after } & & & 0.0633 & \\
\hline & & & {$[0.88]$} & \\
\hline \multirow[t]{2}{*}{ D_30days_before } & & & & $0.139 * *$ \\
\hline & & & & {$[2.25]$} \\
\hline \multirow[t]{2}{*}{ D_30days_after } & & & & 0.0558 \\
\hline & & & & {$[0.96]$} \\
\hline \multirow[t]{2}{*}{ Hệ số chặn } & $0.0390 *$ & 0.0303 & 0.0301 & 0.0247 \\
\hline & {$[1.80]$} & {$[1.35]$} & {$[1.31]$} & [0.98] \\
\hline \multirow[t]{2}{*}{ L.ar } & $0.0876 * * *$ & $0.0846^{* * *}$ & $0.0851 * * *$ & $0.0888 * * *$ \\
\hline & {$[3.25]$} & {$[3.14]$} & [3.16] & [3.31] \\
\hline \multicolumn{5}{|c|}{ Phương trình phương sai } \\
\hline \multirow[t]{2}{*}{ L.arch } & $0.206 * * *$ & $0.205^{* * *}$ & $0.205^{* * *}$ & $0.203^{* * *}$ \\
\hline & {$[7.15]$} & {$[7.13]$} & {$[7.10]$} & {$[7.08]$} \\
\hline \multirow[t]{2}{*}{ L.garch } & $0.739 * * *$ & $0.733 * * *$ & $0.738 * * *$ & $0.745^{* * *}$ \\
\hline & {$[10.22]$} & {$[10.07]$} & {$[10.13]$} & {$[10.15]$} \\
\hline \multirow[t]{2}{*}{ Hệ số chặn } & 0.0309 & 0.0387 & 0.0331 & 0.0275 \\
\hline & {$[0.51]$} & {$[0.63]$} & {$[0.54]$} & {$[0.44]$} \\
\hline Số quan sát & 2518 & 2518 & 2518 & 2518 \\
\hline
\end{tabular}

***,**** tương ứng với mức ý nghĩa $1 \%, 5 \%$ và $10 \%$

Nguồn: Tác giả tính toán từ số liệu thu thập được

Kết quả hồi quy theo mô hình (5) ở Bảng 5 tiếp tục củng cố thêm vai trò của Tết nguyên đán đến thị trường chứng khoán Việt Nam. Tuy nhiên, sự phân tích được thực hiện cụ thể hơn cho giai đoạn trước và sau Tết để thấy rõ sự bất đối xứng trong tác động của Tết đến thị trường.

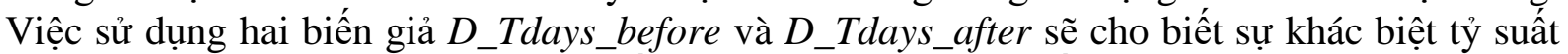
sinh lợi giữa $T$ ngày giao dịch trước Tết, $T$ ngày giao dịch sau Tết với những ngày khác của thị

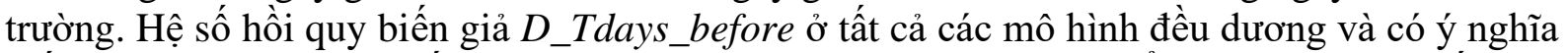
thống kê nhưng độ lớn biến giả này càng giảm khi $T$ càng lớn. Cụ thể, chênh lệch tỷ suất sinh lợi thị trường của những ngày giao dịch trong khung cửa sổ $5 ; 10 ; 15$ và 30 ngày trước Tết với những ngày giao dịch không gần kỳ nghỉ Tết lần lượt giảm dần là $0,33 \% ; 0,32 \% ; 0,23 \%$ và $0,13 \%$. Biến giả $D \_T d a y s \_a f t e r$ mặc dù cũng mang dấu dương nhưng không có ý nghĩa thống kê ở tất cả các phương trình.

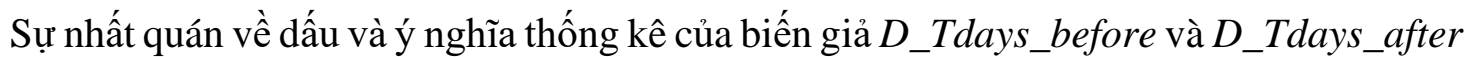
cho thấy rằng tác động của Tết nguyên đán chủ yếu diễn ra ở các ngày giao dịch trước Tết, khi 
sự kiện Tết đang đến gần, chứ không phải diễn ra ở những ngày sau Tết, khi mà Tết đã qua. Có thể nguyên nhân đến từ yếu tố tâm lý hành vi, thị trường sẽ sôi động những ngày trước Tết, khi mà các nhà đầu tư đều muốn có những quyết định đầu tư nhằm đem lại những điều tốt đẹp hoặc thuận lợi cho năm mới sắp đến. Cũng có thể họ muốn chốt lại những điều chưa thuận lợi để khép lại một năm đã qua. Ngược lại, khi truyền thống Á đông thường đề cập đến những sự kiện đầu tiên trong năm mới sẽ ảnh hưởng đến may mắn hoặc thuận lợi cho cả năm nên các thương vụ mua bán diễn ra thận trọng; hoặc do bị ảnh hưởng tâm lý nghỉ ngơi, việc giao dịch trên thị trường chứng khoán sau Tết sẽ ít sôi động như những ngày trước Tết. Vì vậy, kết quả ước lượng của mô hình rất phù hợp với thực tiễn thị trường.

Để phân tích chi tiết hơn hiệu ứng Tết nguyên đán trên thị trường. Bài viết tiếp tục áp dụng mô hình (5) với tỷ suất sinh lợi hàng ngày của 24 ngành trên thị trường. Kết quả phân tích cho số liệu của ngành được thể hiện ở Bảng 7 và Bảng 8 . Đối với việc phân tích ngành, chỉ độ

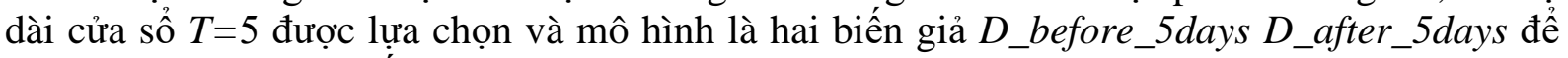
tránh trường hợp các kết quả được trình bày quá dài. 


\section{Bảng 6}

Kiểm định hiệu ứng Tết nguyên đán cho từng ngành

\begin{tabular}{|c|c|c|c|c|c|c|c|c|c|c|c|c|}
\hline & \multicolumn{12}{|c|}{ Tỷ suất sinh lọ̣i } \\
\hline Biến độc lập & $\begin{array}{c}\text { Bất động } \\
\text { sản }\end{array}$ & Cao su & $\begin{array}{l}\text { Chứng } \\
\text { khoán }\end{array}$ & $\begin{array}{l}\text { Công } \\
\text { nghệ }\end{array}$ & Dầu khí & Dịch vụ & $\begin{array}{c}\text { Đầu tư } \\
\text { phát } \\
\text { triển }\end{array}$ & $\begin{array}{c}\text { Đầu tư } \\
\text { xây dụng }\end{array}$ & $\begin{array}{l}\text { Dược } \\
\text { phẩm }\end{array}$ & $\begin{array}{l}\text { Dịch vụ } \\
\text { công ích }\end{array}$ & Giáo dục & $\begin{array}{c}\text { Hàng } \\
\text { không }\end{array}$ \\
\hline \multicolumn{13}{|c|}{ Phương trình trung bình } \\
\hline \multirow[t]{2}{*}{ D_5days_before } & $0.35^{*}$ & $0.38 *$ & 0.44 & 0.28 & 0.251 & 0.285 & 0.511 & 0.284 & $0.50 * * *$ & 0.0799 & 0.166 & 0.012 \\
\hline & {$[1.92]$} & {$[1.71]$} & {$[1.62]$} & {$[1.31]$} & {$[0.74]$} & [1.47] & {$[1.36]$} & {$[1.22]$} & [3.64] & {$[0.17]$} & {$[0.70]$} & {$[0.03]$} \\
\hline \multirow[t]{2}{*}{ D_5days_after } & $0.39 * *$ & $0.48 * *$ & 0.33 & 0.134 & $0.468 *$ & $1.25 * * *$ & 0.284 & 0.309 & 0.271 & $0.716^{* *}$ & 0.0708 & 0.351 \\
\hline & [2.41] & [2.30] & {$[1.55]$} & {$[0.87]$} & {$[1.71]$} & {$[18.46]$} & {$[0.88]$} & {$[1.61]$} & {$[1.47]$} & {$[2.41]$} & {$[0.30]$} & {$[0.97]$} \\
\hline \multirow[t]{2}{*}{ Hệ số chặn } & 0.0112 & -0.003 & -0.02 & $0.07 * * *$ & 0.0345 & 0.00776 & 0.0351 & 0.0332 & 0.0187 & 0.00 & $0.08 * * *$ & $0.08 * *$ \\
\hline & {$[0.36]$} & {$[-0.11]$} & {$[-0.53]$} & {$[2.72]$} & {$[0.86]$} & {$[0.25]$} & {$[0.84]$} & [1.12] & {$[0.78]$} & {$[0.00]$} & [2.76] & [2.23] \\
\hline \multirow[t]{2}{*}{ L.ar } & $0.06 * * *$ & $0.06 * *$ & $0.06 * *$ & 0.0116 & $0.07 * * *$ & $0.09 * * *$ & $0.13 * * *$ & 0.0205 & $0.09 * * *$ & -0.06 & -0.04 & 0.0213 \\
\hline & {$[2.83]$} & {$[2.41]$} & {$[2.51]$} & {$[0.46]$} & {$[2.81]$} & {$[3.87]$} & {$[5.29]$} & {$[0.86]$} & {$[3.73]$} & {$[-2.10]$} & {$[-1.92]$} & {$[0.87]$} \\
\hline \multicolumn{13}{|c|}{ Phương trình phương sai } \\
\hline \multirow[t]{2}{*}{ L.arch } & $0.07 * * *$ & $0.09 * * *$ & $0.08 * * *$ & $0.10 * * *$ & $0.12 * * *$ & $0.22 * * *$ & $0.23 * * *$ & $0.11 * * *$ & $0.17 * * *$ & $0.15^{* * *}$ & $0.07 * * *$ & $0.21 * * *$ \\
\hline & {$[9.27]$} & {$[9.48]$} & {$[10.06]$} & [7.16] & [9.41] & {$[15.30]$} & [10.08] & [7.01] & {$[10.36]$} & [9.97] & [9.98] & [13.29] \\
\hline \multirow[t]{2}{*}{ L.garch } & $0.91 * * *$ & $0.88 * * *$ & $0.92 * * *$ & $0.83 * * *$ & $0.84 * * *$ & $0.77 * * *$ & $0.64 * * *$ & $0.84 * * *$ & $0.74 * * *$ & $0.87 * * *$ & $0.91 * * *$ & $0.82 * * *$ \\
\hline & [104.62] & [76.43] & [128.36] & [35.63] & [55.49] & [69.39] & [22.60] & [36.84] & [31.09] & [89.56] & [132.46] & [93.83] \\
\hline \multirow[t]{2}{*}{ Hệ số chặn } & $0.04 * * *$ & $0.06 * * *$ & $0.02 * * *$ & $0.11 * * *$ & $0.13 * * *$ & $0.12 * * *$ & $0.62 * * *$ & $0.10 * * *$ & $0.11 * * *$ & $0.023^{*}$ & $0.05 * * *$ & $0.07 * * *$ \\
\hline & [5.90] & [4.85] & [3.37] & {$[6.06]$} & [5.75] & [10.07] & [10.30] & [4.16] & [6.35] & [1.68] & [4.87] & [6.95] \\
\hline Số quan sát & 1992 & 1992 & 1992 & 1992 & 1992 & 1992 & 1992 & 1992 & 1992 & 1064 & 1992 & 1807 \\
\hline
\end{tabular}

Nguồn: Kết quả xử lý từ dữ liệu điều tra 


\section{Bảng 7}

Kiểm định hiệu ứng Tết nguyên đán cho từng ngành (tiếp theo)

\begin{tabular}{|c|c|c|c|c|c|c|c|c|c|c|c|c|}
\hline & \multicolumn{12}{|c|}{ Tỷ suất sinh lọi } \\
\hline Biến độc lập & $\begin{array}{c}\text { Khoáng } \\
\text { sản }\end{array}$ & $\begin{array}{l}\text { Năng } \\
\text { lượng }\end{array}$ & $\begin{array}{l}\text { Ngân } \\
\text { hàng }\end{array}$ & Nhựa & $\begin{array}{c}\text { Sản xuất } \\
\text { kinh } \\
\text { doanh }\end{array}$ & Thép & $\begin{array}{l}\text { Thực } \\
\text { phẩm }\end{array}$ & $\begin{array}{c}\text { Thương } \\
\text { mại }\end{array}$ & Thủy sản & Vận tải & $\begin{array}{l}\text { Vật liệu } \\
\text { xây dựng }\end{array}$ & $\begin{array}{c}\text { Xây } \\
\text { dựng }\end{array}$ \\
\hline \multicolumn{13}{|c|}{ Phương trình trung bình } \\
\hline \multirow[t]{2}{*}{ D_5days_before } & 0.287 & $0.48 * * *$ & 0.349 & 0.224 & $0.404 *$ & 0.327 & 0.186 & 0.25 & 0.458 & 0.265 & $0.474 *$ & $0.448^{*}$ \\
\hline & {$[1.06]$} & {$[3.88]$} & {$[0.91]$} & {$[0.79]$} & {$[1.95]$} & {$[1.52]$} & {$[0.71]$} & {$[1.21]$} & {$[1.56]$} & {$[1.41]$} & {$[1.77]$} & {$[1.88]$} \\
\hline \multirow[t]{2}{*}{ D_5days_after } & 0.376 & -0.0256 & 0.266 & 0.263 & 0.221 & $0.81 * * *$ & 0.237 & $0.330^{*}$ & 0.0387 & $0.299 *$ & 0.116 & 0.362 \\
\hline & {$[1.34]$} & {$[-0.15]$} & {$[0.98]$} & {$[1.45]$} & {$[1.59]$} & {$[3.08]$} & {$[1.17]$} & {$[1.81]$} & {$[0.18]$} & {$[1.93]$} & {$[0.64]$} & {$[1.30]$} \\
\hline \multirow[t]{2}{*}{ Hệ số chặn } & $-0.06^{* *}$ & $0.06 * *$ & 0.0265 & 0.0291 & $0.04 *$ & 0.0163 & 0.0236 & $0.07 * *$ & 0.0364 & -0.00756 & $0.06^{*}$ & $0.10^{* *}$ \\
\hline & {$[-2.37]$} & {$[2.54]$} & {$[0.89]$} & {$[1.10]$} & {$[1.68]$} & {$[0.46]$} & {$[1.03]$} & {$[2.51]$} & {$[1.00]$} & {$[-0.32]$} & {$[1.76]$} & {$[2.28]$} \\
\hline \multirow[t]{2}{*}{ L.ar } & $0.14 * * *$ & 0.00865 & $0.07 * * *$ & -0.01 & $0.08 * * *$ & 0.018 & $0.0426 *$ & $0.07 * * *$ & $0.126^{* * *}$ & 0.0117 & $0.07 * * *$ & $0.10 * * *$ \\
\hline & {$[6.45]$} & {$[0.38]$} & {$[2.80]$} & {$[-0.39]$} & {$[3.65]$} & {$[0.75]$} & {$[1.87]$} & {$[2.91]$} & {$[5.43]$} & {$[0.51]$} & {$[3.19]$} & {$[3.84]$} \\
\hline \multicolumn{13}{|c|}{ Phương trình phương sai } \\
\hline \multirow[t]{2}{*}{ L.arch } & $0.19 * * *$ & $0.10 * * *$ & $0.11 * * *$ & $0.08 * * *$ & $0.07 * * *$ & $0.08 * * *$ & $0.12 * * *$ & $0.09 * * *$ & $0.08 * * *$ & $0.09 * * *$ & $0.12 * * *$ & $0.19 * * *$ \\
\hline & [16.25] & [9.59] & [8.37] & [9.13] & {$[8.42]$} & [8.51] & [8.81] & [6.69] & [6.12] & [8.43] & [8.15] & {$[9.22]$} \\
\hline \multirow[t]{2}{*}{ L.garch } & $0.81 * * *$ & $0.87 * * *$ & $0.85^{* * *}$ & $0.89 * * *$ & $0.91 * * *$ & $0.89 * * *$ & $0.84 * * *$ & $0.85^{* * *}$ & $0.86^{* * *}$ & $0.88 * * *$ & $0.84 * * *$ & $0.76^{* * *}$ \\
\hline & [102.48] & [72.33] & [51.85] & [70.67] & [92.95] & {$[67.42]$} & [50.10] & [40.65] & [37.60] & [61.08] & [41.99] & [34.81] \\
\hline \multirow[t]{2}{*}{ Hệ số chặn } & $0.12 * * *$ & $0.04 * * *$ & $0.08 * * *$ & $0.05 * * *$ & $0.02 * * *$ & $0.09 * * *$ & $0.06^{* * *}$ & $0.09 * * *$ & $0.12 * * *$ & $0.03 * * *$ & $0.10 * * *$ & $0.19 * * *$ \\
\hline & [11.06] & [5.15] & {$[6.24]$} & [4.65] & {$[3.56]$} & {$[5.08]$} & {$[5.62]$} & [4.87] & [3.97] & [4.16] & [4.92] & {$[6.82]$} \\
\hline Số quan sát & 1992 & 1992 & 1992 & 1992 & 1994 & 1992 & 1992 & 1992 & 1994 & 1992 & 1992 & 1767 \\
\hline
\end{tabular}

Nguồn: Kết quả xử lý từ dữ liệu điều tra 
Kết quả thể hiện ở Bảng 7 và Bảng 8 cho thấy rằng mặc dù hiệu ứng Tết nguyên đán tồn tại trên thị trường, đại diện bằng chỉ số VN-Index nhưng chỉ có một số ngành tồn tại hiệu ứng này. Trong số 24 ngành được thu thập dữ liệu và đưa vào xem xét, bằng chứng thống kê về hiệu ứng trước Tết nguyên đán được tìm thấy ở ngành Bất động sản, cao su, dược phẩm, năng lượng, sản xuất kinh doanh, vật liệu xây dựng và xây dựng. Các ngành bất động sản, cao su, dầu khí, dịch vụ, dịch vụ công ích, thép, thương mại và vận tải có hiệu ứng sau Tết nguyên đán. Đặc biệt, thị trường bất động sản và cao su có ý nghĩa thống kê ở cả hai biến giả trước và sau Tết nguyên đán. Các ngành còn lại chưa tìm thây bằng chứng về hiệu ứng Tết nguyên đán bao gồm ngành chứng khoán, công nghệ, đầu tư phát triển, đầu tư xây dựng, giáo dục, khoáng sản, ngân hàng, nhựa, thực phẩm và thủy sản.

\section{Kết luận và một số hàm ý của nghiên cứu}

Bài viết sử dụng số liệu về giá đóng cửa chứng khoán hàng ngày của chỉ số VN-Index trong thời gian từ đầu tháng 01 năm 2010 đển cuối tháng 12 năm 2019 để kiểm định sự tác động của kỳ nghỉ Tết nguyên đán đến thị trường. Kết quả phân tích số liệu cho thấy Tết nguyên đán có tác động tích cực đến thị trường, cụ thể là tỷ suất sinh lợi trung bình của các giai đoạn 5 ngày; 10 ngày; 15 ngày và 30 ngày xung quanh kỳ nghỉ Tết nguyên đán đều cao hơn tỷ suất sinh lợi trung bình của những ngày giao dịch khác. Khi xét thời gian càng cách xa ngày Tết thì tỷ suất sinh lợi trung bình càng giảm. Ngoài việc kết luận về tác động tích cực của ngày Tết nguyên đán, kết quả của bài viêt còn cho thấy tác động của ngày Tết nguyên đán thể hiện rõ rệt ở những ngày giao dịch trước Tết chứ không xảy ra ở những ngày sau Tết.

Bài viết còn thực hiện kiểm định phân tích hiệu ứng Tết nguyên đán trong từng ngành và cho thấy sự hiện diện hiệu ứng trước Tết nguyên đán ở các ngành Bất động sản, cao su, dược phẩm, năng lượng, sản xuất kinh doanh, vật liệu xây dựng và xây dựng. Các ngành bất động sản, cao su, dầu khí, dịch vụ, dịch vụ công ích, thép, thương mại và vận tải có hiệu ứng sau Tết nguyên đán. Số liệu của các ngành chứng khoán, công nghệ, đầu tư phát triển, đầu tư xây dựng, giáo dục, khoáng sản, ngân hàng, nhựa, thực phẩm và thủy sản chưa cho thấy sự tác động của hiệu ứng Tết nguyên đán.

Thông qua việc kiểm định tác động của Tết nguyên đán đến thị trường chứng khoán, bài viết còn có ý nghĩa thực tiễn khi cung cấp thêm bằng chứng chứng thực nghiệm cho tính không hiệu quả của thị trường chứng khoán Việt Nam bên cạnh các hiệu ứng khác như hiệu ứng ngày thứ Hai, hiệu ứng ngày cuối tuần, hiệu ứng chuyển tháng đã được kiểm định trước đó. Hiệu ứng Tết nguyên đán có ý nghĩa thống kê cho thấy tính hình mẫu trong số liệu thị trường, khi mà dựa vào đó nhà đầu tư có thêm thông tin để có thể tìm kiếm tỷ suất sinh lợi bất thường.

\section{Tài liệu tham khảo}

Dichev, I. D., \& Janes, T. D. (2001). Lunar cycle effects in stock returns. Journal of Private Equity, 6(4), 8-29.

Fama, E. F. (1970). Efficient capital markets: A review of theory and empirical work. The Journal of Finance, 25(2), 383-417.

Le, M. T. H., \& Truong, S. N. (2018). Ảnh hưởng của kỳ nghỉ Tết Âm lịch đến thị trường chứng khoán Việt Nam và các quốc gia châu Á [The influence of the Lunar New Year holiday on Vietnam Stock Markets and other Asian countries]. Tạp chí Công nghệ Ngân hàng, $142 \& 143,90-100$. 
Tram, H. T. X., Vo, V. X., \& Nguyen, C. P. (2015). Hiệu ứng ngày thứ hai trước và sau khủng hoảng trên thị trường chứng khoán Việt Nam trước và sau khủng hoảng [The effect of the second day before and after the crisis in the Vietnam stock market before and after the crisis]. Tạp chí Phát triển và hội nhập, 20(30), 55-60.

Yuan, K., Zheng, L., \& Zhu, Q. (2006). Are investors moonstruck? Lunar phases and stock return. Journal of Empirical Finance, 13(1), 1-23.

Yuan, T., \& Gupta, K. (2014). Chinese Lunar New Year effect in Asian stock markets, 19992012. The Quarterly Review of Economic and Finance, 54(4), 529-537. 